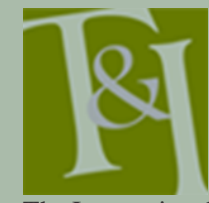

The International Journal for Translation \& Interpreting Research trans-int.org

\section{Caution and compliance in medical encounters: Non-interpretation of hedges and phatic tokens}

\section{Michaela Albl-Mikasa}

Zurich University of Applied Sciences

michaela.albl-mikasa@zhaw.ch

\section{Elisabeth Glatz}

Zurich University of Applied Sciences

elisa.glatz@gmail.com

\section{Gertrud Hofer}

Zurich University of Applied Sciences

xhog@zhaw.ch

\section{Marina Sleptsova}

University Hospital Basel

marina.sleptsova@usb.ch

DOI: 10.12807/ti.107203.2015.a06

\begin{abstract}
Our paper is based on the Swiss research project 'Interpreting in Medical Settings: Roles, Requirements and Responsibility', which was supported by a grant of the Swiss Commission for Technology and Innovation (KTI) and carried out by an interdisciplinary team comprising medical specialists from the University Hospital of Basel (Marina Sleptsova and colleagues) and interpreting studies/applied linguistics researchers from the Zurich University of Applied Sciences (ZHAW) (Gertrud Hofer and colleagues). It explores videotape transcriptions of 12 authentic interpreted conversations between German speaking doctors/medical staff and patients of Turkish or Albanian origin. The analysis finds that culture-specific expressions produced by the patients occur rarely and do not pose any interpreting problems. By contrast, phatic tokens and hedges play an important role in medical personnel's presentation of their interactional, trust building, diagnostic and therapeutic intentions. Although these expressions are essential communication elements geared at building patients' compliance and establishing doctors' safeguards, they are rarely or inconsistently rendered by the interpreters. It is argued that, while medical interpreters may have plausible reasons not to render these expressions, they would still need to be made aware of the significance of such pragmatic aspects of communication in training courses and/or pre-encounter briefings. More generally, empirical research - similar to that on questioning style and questioning techniques should focus more on the exploration of discourse markers, meta-discourse comments and rapport-building expressions of different types of utterance and discourse practices in healthcare interpreting settings.
\end{abstract}

Keywords: medical interpreting, cultural expressions, phatic tokens, hedges, metadiscourse markers

\section{Introduction to the data}

Our paper is based on the Swiss research project "Interpreting in Medical Settings: Roles, Requirements and Responsibility", which was supported (from 2010 to 2012) by a grant of the Swiss Commission for Technology and 
Innovation (KTI). The project was conducted by an interdisciplinary team comprising medical specialists from the University Hospital of Basel (Marina Sleptsova and colleagues) and interpreting studies/applied linguistics researchers from the Zurich University of Applied Sciences (ZHAW) (Gertrud Hofer and colleagues). The core of their empirical results consists of 19 authentic, interpreted conversations along with a broad, questionnaire-based survey regarding the role of interpreters as perceived by medical personnel as well as medical interpreters. For reasons of comparison this survey was conducted in three different countries: England, Ireland and Switzerland. It used an adapted version of Angelelli's (2004) Interpreter Interpersonal Role Inventory (IPRI). The latter was complemented by a comprehensive review of existing literature on the role of medical interpreters (cf. Sleptsova et al. 2014). In the interpreted conversations (14.42 h, $856 \mathrm{~min}$ ), German and Swiss-German speaking doctors and healthcare personnel interacted with patients of Turkish and Albanian origin at the university hospitals of Basel and Zurich and the Inselspital Bern. The encounters were video-recorded and transcribed using the transcription software EXMARaLDA. The Turkish and Albanian parts were translated and the translations double-checked. However, it remains a methodological limitation that the analysts, unable to understand the Turkish and Albanian originals, cannot guarantee the accuracy of the translations.

For the KTI project, the data was divided into 3866 segments, consisting of "continuous sections of dialogue in a single language, plus any translation of that dialogue" (Laws et al., 2004, p. 71); in other words, a segment comprised the original utterance and its interpreted version. The data set was then subjected to qualitative and quantitative analysis, using the code-based software ATLAS.ti for qualitative analysis. Rating of interpreter performance was conducted by two linguists and one psychologist, covering six categories: 'omission', 'addition', 'vague rendition', 'inaccurate rendition', 'terminologyrelated features', and 'role/perspective change'. Quantitative and qualitative analysis of results revealed an unexpected degree of seemingly unprofessional behaviour by both parties in charge of communication. Healthcare professionals were observed to be talking too much and for too long, addressing patients in the third person, not requesting clarification from interpreters when faced with incomprehensible renditions, not intervening when interpreters were taking too much initiative or when patients talked for too long, and generally showing little confidence regarding their conversational role in the encounter. All in all, they did not exhibit the professional attitude necessary for supporting interpretermediated communication. On the part of the interpreters, an unexpectedly high deviation rate was observed (omissions, additions, vague renditions, inaccurate renditions) as well as constant switches in perspective (between first and third person address as well as formal and informal forms); especially the latter pointed to insecurity on the part of the interpreters regarding their role (cf. Sleptsova et al., 2015).

This raises the question as to the level of training and experience of the interpreters. All interpreters in the project had Albanian or Turkish as their first and German as their second language. It was optional for them to fill in an anonymous form stating their background; the authors realize that this is a shortcoming because only the ten Basel-based interpreters of the 19 interpreters supplied the additional information. Five of these Basel-based interpreters had a certificate of professional continuous training which they gained following 150 hours of seminars and home study to introduce them to the basics of the techniques, professional behaviour and settings of community interpreting (INTERPRET 2015b). Within this training they were tested for B2 language levels ${ }^{1}$ in German, the Swiss regional language, and were supposed to have at

\footnotetext{
${ }^{1}$ The Common European Framework of Reference (http://www.coe.int/t/dg4/linguistic/source/ framework_en.pdf, accessed 15/5/15) describes a B2 level of foreign language proficiency as 
least 50 hours working experience in public service interpreting. Another four of the interpreters were in the process of completing this or similar training. It is highly likely that the nine interpreters from the Zurich and Bern hospitals who did not fill in the form had a similar background because hospitals in Switzerland usually contract medical interpreters through the Kanton-based service providers (e.g., HEKS Basel, comprendi? Bern, AOZ Medios Zurich, see INTERPRET 2015a) - unless they fall back on ad hoc interpreters, which was not the case in this study.

\section{Quantitative analysis - phatics}

As a follow-up to the KTI project, a further analysis focused on distinctive features that affected communication but had not been in the foreground of the KTI analysis. During screening of the recordings and transcripts, it had become clear that the percentage of non-interpreted utterances or non-interpretermediated communication was relatively high, while culture-specific terms (see Section 2.1 for a definition) or culture-bound stretches introduced into the conversation by the patients were rare. Moreover, it was striking that the use of phatic expressions (see Section 2.1 for a definition) was relatively frequent on the part of the healthcare professionals, but that these expressions were generally omitted in the interpretations. Close analysis of 12 (of the 19) transcripts showed that 468 of an overall 1939 segments (24.1\%) remained unmediated. Only 23 of those 1939 segments (or 1.2\%) contained culturespecific elements. 184 segments $(9.5 \%$ of the total) contained phatic expressions, of which only 18 (9.8\%, or one tenth) were interpreted.

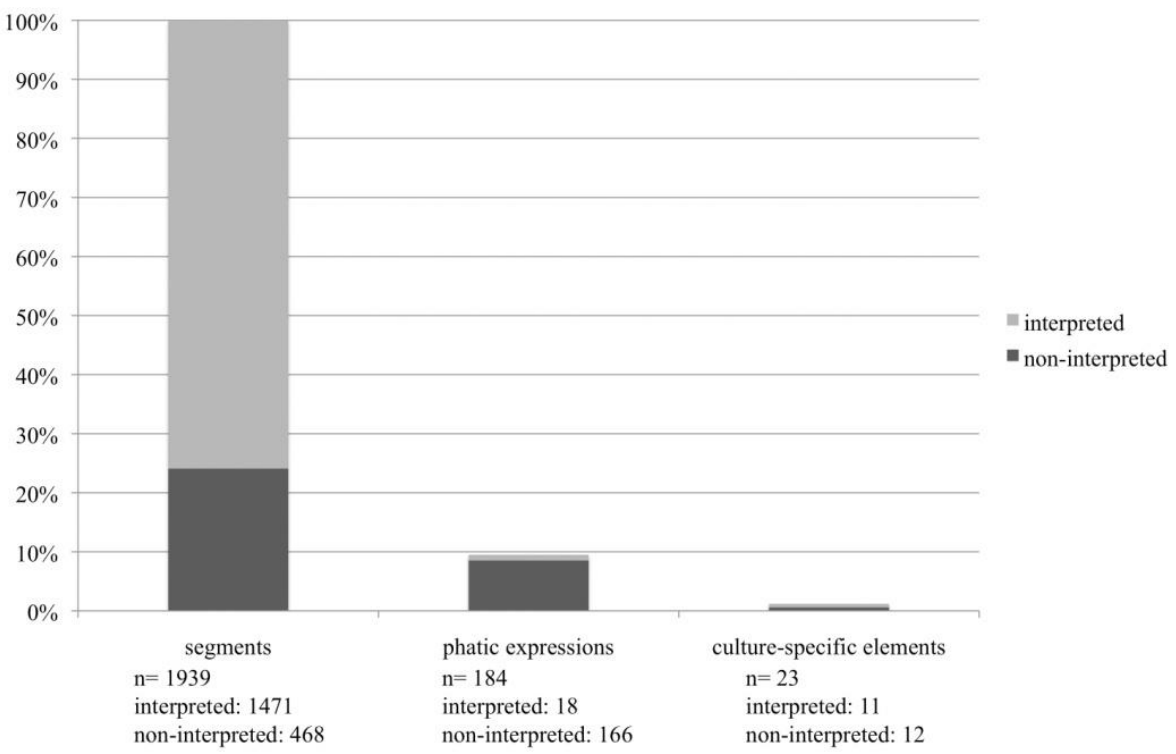

Figure 1. Overall number of culture-specific and phatic expressions, as well as interpreted vs. non-interpreted segments

\subsection{Culture-related expressions}

Saying that culture-specific expressions occurred infrequently in the data at hand (in just over $1 \%$ of segments) invites the question as to what kind of linguistic items we looked for. Culture is a concept that has been defined in multiple ways. Today, it is mostly understood to refer to the knowledge and

follows: "Can understand the main ideas of complex text on both concrete and abstract topics, including technical discussions in his/her field of specialisation. Can interact with a degree of fluency and spontaneity that makes regular interaction with native speakers quite possible without strain for either party. Can produce clear, detailed text on a wide range of subjects and explain a viewpoint on a topical issue giving the advantages and disadvantages of various options." (p. 24) 
experience embraced by a group or collective of people (Wikan, 2002, p. 80), whereby each individual has access to and is involved in a multitude of partly overlapping communities or discourse systems (Scollon \& Wong-Scollon, 2001, p. 138). Against this background, "culture-related expressions" were taken to be those that reflected a frame of reference not shared between the participants of the encounter, namely, expressions used by patients that would not conventionally be used by native speakers of Swiss German or French in the Swiss context. In the KTI data, such expressions, when they occurred, were often in reference to God or religious aspects, or in the area of paying respect or showing appreciation (e.g. Ich bin zufrieden mit meinem Arzt. Wo sie hinkommt, verlass ich sie nicht; [I'm perfectly happy with my doctor. Wherever she goes, I will not leave her]).

Table 1. Breakdown per video-recorded encounter

\begin{tabular}{|l|l|l|l|l|}
\hline Video & $\begin{array}{l}\text { No. of } \\
\text { segments }\end{array}$ & $\begin{array}{l}\text { Cultural } \\
\text { expressions } \\
\text { (of which } \\
\text { interpreted) }\end{array}$ & $\begin{array}{l}\text { Phatic tokens } \\
\text { (of which } \\
\text { interpreted) }\end{array}$ & $\begin{array}{l}\text { Non-interpreted } \\
\text { segments }\end{array}$ \\
\hline 1 & 140 & $4(0)$ & $23(0)$ & $52(37.1 \%)$ \\
\hline 2 & 121 & $6(0)$ & $9(1)$ & $41(33.9 \%)$ \\
\hline 3 & 465 & $2(2)$ & $28(10)$ & $21(4.5 \%)$ \\
\hline 4 & 223 & $0(0)$ & $24(4)$ & $113(50.7 \%)$ \\
\hline 5 & 152 & $0(0)$ & $15(0)$ & $42(27.6 \%)$ \\
\hline 10 & 193 & $2(0)$ & $22(3)$ & $69(35.8 \%)$ \\
\hline 11 & 86 & $1(1)$ & $8(0)$ & $10(11.6 \%)$ \\
\hline 13 & 95 & $1(1)$ & $21(0)$ & $36(37.9 \%)$ \\
\hline 15 & 122 & $1(1)$ & $9(0)$ & $24(19.7 \%)$ \\
\hline 17 & 211 & 0 & $12(0)$ & $10(16.7 \%)$ \\
\hline 18 & 60 & $3(3)$ & $12(0)$ & $10(16.7 \%)$ \\
\hline 19 & 71 & $3(3)$ & $1(0)$ & $40(56.3 \%)$ \\
\hline
\end{tabular}

In the twelve encounters analysed, these kinds of expressions were irrelevant from the interpreters' points of view, in that they did not create any major interpreting problems. This may have to do with the fact that the interpreters shared the patients' cultural background, but it can also be taken as an indicator that the construct of 'culture' is often overrated in such settings, as is also suggested by Scollon and Wong-Scollon's quotation "cultures do not talk to each other, individuals do" (2001, p. 138). The analysis confirms results by Felberg and Skaaden (2012), who oppose the practice of professionals in charge of the dialogue ascribing problems in medical encounters to 'culture', i.e. using 'culture' as a pretext for devolving

responsibility for conversational management to interpreters. As mentioned above, however, culture-related expressions were rarely used by the patients and, therefore, did not play a central role in the data.

\subsection{Phatic expressions}

By contrast, the KTI data abound with phatic expressions (contained in almost $10 \%$ of segments) used by the healthcare professionals. According to Laver (1975), phatic expressions carry social functions rather than contributing to conversational content; that is, their main function is that of building rapport. Laver distinguishes (1) "neutral tokens", pointing to the situational context (weather, view, current topics), (2) "self-oriented tokens", which are of personal nature and reflect the speaker's perspective (My, I'm hot today) and (3) "otheroriented tokens", which are of personal relevance and oriented towards the addressee (How are you?). We extended that definition to include metadiscourse comments and gambits or backchannels, whenever they had a phatic function. The multitude of phatic expressions in the transcribed encounters were phrases such as jetzt fangen wir an [now let's start]; und jetzt habe ich als erstes 
ne Frage [and now first of all, I have a question]; prima, ja super [wonderful, yes, very good]; ist gut machen wir das so [ok, fine, let's do it that way]; toll, schön [wonderful, nice]; und dann sagen Sie mir mal [and then tell me]; $O K$, dann müssen wir schauen [ok, we'll have to see about that]; prima, dann wären wir so weit [good, then this would be it]; also es geht darum [so, the thing is]; jetzt machen wir Folgendes [let's try the following], etc.

While several healthcare professionals in a number of project-related meetings emphasized the importance of such expressions in developing a relationship of confidence and trust with the patient - a function that carries diagnostic and therapeutic value by reason of the psychological dimension of these medical conversations - they were almost all systematically omitted in the interpretations. As the psychologists and communication experts at the University Hospital Basel indicated in those meetings, the importance of these expressions lies in the fact that it is not only impossible to predict the direction in which the dialogue will develop, but that this kind of open-endedness is also important for medical purposes. In the encounter, scope should be left for the healthcare professional to come to understand the situation from the patient's own perspective and to assess from the reactions to the healthcare professional's rapport-building efforts the patient's frame of mind and willingness to open up.

It is arguable that phatic expressions, too, are culture-bound, and that Turkish and Albanian-speaking medical professionals might use such expressions differently in their effort to build rapport. This, in turn, may explain why the Turkish and Albanian medical interpreters did not interpret these phrases, considering them to be pragmatically inappropriate in the target language. Due to the Kantonal Ethical Review Board's strict guidelines on anonymizing data and participants, it was not possible to trace the interpreters and engage them in retrospective interviews. However, the tone in the examples given above seems to be of a more generally social rather than culture-specific nature. Moreover, the handling of the above expressions by the interpreters seems to be in line with Hale's findings regarding that of similar features in courtroom discourse practices:

A majority of interpreters demonstrated a lack of understanding of the specific purposes of certain question types, including the use of tags and other questioning strategies, such as discourse markers, repetition and modality. The majority of interpreters arbitrarily altered or omitted these features in their rendition of the questions, changing their pragmatic intention and force (2007, p. 95).

Interestingly, when Hale presented examples extracted from her data to practising interpreters they followed the same pattern as the interpreters in the sample, despite the advantage of having the data utterances right in front of them. Hale, therefore, concludes that it may be a matter of "adequate training $[\ldots]$ for interpreters to understand the reasons behind certain linguistic features and the significance of language style" $(2007$, p. 96) in particular interpreting settings.

In a similar way, in our data, the importance of these interactionally relevant expressions was apparently not clear to the interpreters: less than $10 \%$ of all phatic expressions were actually rendered in target discourse production. Apart from denoting a lack of professional understanding of their significance, omission of these elements may also have been due to reasons pertaining to constraints inherent in the interpreting process. The taxing interpreting situation necessitates economical use of limited resources (cf. Giles' 2009 Efforts Model), so that condensation or "the omission of non-content features, such as hesitations, discourse markers, repetitions and backtrackings" (Hale 2007: 10) is likely to become part of the interpreters' capacity management. This may be true, in particular, of phatic expressions, the function of which is not primarily informative, so that they may have been considered redundant, to some extent, 
by the interpreters. It must be taken into consideration here that healthcare interpreters often work under conditions that are very different from those of conference interpreters, who would routinely take turns with a colleague in the booth every 30 minutes. In the data under analysis, the duration of interaction to be handled by a single interpreter generally exceeded 30 minutes; in one case a medical assessment conversation ran for three hours, with only three short breaks. Under such conditions, it is very difficult to satisfy vital requirements, even if this

requirement to maintain stylistic features in the interpreter's rendition is crucial in certain settings, such as the courtroom or a medical consultation. In these settings demeanour and discourse style, which form the manner in which a testimony is presented or a condition described, are essential in the evaluation of witness character or a patient's diagnosis [...] (Hale, 2007, p. 11).

In order to fulfil this requirement of rendering phatic expressions in interpreter-mediated doctor-patient encounters, (a) interpreters need to be informed, both during training and as part of the pre-service guidelines, that these elements are not redundant, but carry vital information from a functional point of view and (b) working conditions need to be adjusted, so that medical interpreters have the capacity to implement this requirement. In this context, it is interesting to note that lack of professionalism on the part of the medical interpreters could indeed be one reason behind the remarkable extent of nonrendered phatic expressions, as it also appears to be reflected in the high percentage of non-interpreter-mediated, autonomous speech production in the interpreted encounters (almost $25 \%$ of all segments).

Another possibility, in addition to the lack of professional attitude and the question of management of cognitive resources, is that non-interpretation of phatic expressions might be tantamount to some kind of avoidance strategy. By omitting rapport-building and affective expressions, the interpreter can sidestep identification with the person who is engaged in rapport-building, and remain on a more detached level. Especially when healthcare interpreters come from cultural backgrounds where doctors are "authority figures", telling the patient what to do rather than taking a consultative approach, they might be reluctant to become involved in this part of the communication. Again, it may be important to raise their awareness of the more actor-like components of their task and the need to overcome apprehensions or reservations of slipping, as it were, into the healthcare professional's white coat, which is generally associated with authority. At the same time, this is another indicator of the public service interpreter's difficult task of having to approximate the performance of two largely disparate speakers. All in all, a number of factors may play a role in the interpreters' handling of phatic expressions. This would need to be subjected to further research.

\section{Qualitative analysis - hedges}

Against the backdrop of this overall analysis, a more detailed qualitative look was taken within a BA thesis by Elisabeth Glatz (2014) (supervised by Michaela Albl-Mikasa) from the double perspective of Glatz' longstanding experience as a qualified senior nurse and applied linguistics student. The focus was on the expression of cautioning by healthcare professionals, which served the double purpose of compliance building and safeguarding, and how this was rendered by the interpreters. Appropriate communication is essential, but not always easy, in ensuring patients' compliance or cooperation with doctors' suggested treatments, especially when a further layer of complexity is added with the interpreter being part of the interaction (cf. Hale, 2007, p. 40). The first four 
videos that dealt with initial encounters aimed at clarifying patients' medical history - i.e. videos one, two, three and five - were analysed in detail with a focus on hedging or the "strategy by which speakers mitigate and soften the force of their utterances" (Nikula, 1997, p. 192).

According to Thomas (2013), the use of hedging is essential in the psychotherapist's effort to build rapport, which, in turn, is the basis of compliance or a patient's willingness to open up and enter into a cooperative and joint effort with the healthcare professional, without which the success of diagnosis and therapy cannot be secured. Hedging softens the fundamentally asymmetrical and hierarchical relationship between the healthcare professional and the patient in that it signals elements of uncertainty, conveys a sense of the doctor not being omniscient, points to the suggestive rather than instructive character of his or her words and stresses the patient's final say in the matter. Such a patient-centred approach by healthcare professionals aims at:

eliciting and understanding their patient's perspectives, including their concerns, expectations, needs, feelings and ideas; understanding their patients within their unique psychosocial context; reaching a shared understanding of the problem and its treatment with their patients' values; and helping patients to share power and responsibility by involving them in choices to the degree they wish (Krystallidou, 2012, p. 75).

Moreover, such an approach is important from a legal perspective, in that a realistic appraisal and the qualifying or modification of potential therapeutic success safeguards doctors against possible malpractice suits.

Hedging was originally conceived by Lakoff (1972) as enacted by means of expressions such as

Real, regular, actually, almost, as it were, basically, can be viewed as, crypto-, especially, essentially, exceptionally, for the most part, in a manner of speaking, in a real sense, in a sense, in a way, kind of, largely, literally, loosely speaking, more or less, mostly, often, on the tall side, par excellence, particularly, pretty much, principally, pseudo-, quintessentially, rather, really, relatively, roughly, so to say, somewhat, sort of, strictly speaking, technically, typically, very, virtually (Kaltenböck, 2010, p. 17).

The concept has meanwhile been extended to cover not only formal but also functional aspects and, thus, a much broader range of mitigating and softening linguistic expressions.

Hedges are first and foremost the product of a mental attitude which looks for proto-typical linguistic forms (such as modals, epistemic verbs, approximators, etc.) for its realization, but these linguistic forms do not always carry a hedging nuance (Salager-Meyer, 1994, p. 4).

In fact, from a functional point of view, there is no grammatical category of hedges, but it is the use of an expression as a hedging function that makes it a hedge.

There is no limit to the linguistic expressions that can be considered as hedges [...]. The difficulty with these functional definitions is that almost any linguistic item or expression can be interpreted as a hedge [...]. No linguistic items are inherently hedges but can acquire this quality depending on the communicative context or the co-text. This also means that no clear-cut lists of hedging expressions are possible (Clemen, 1997, p. 6).

Applying such a broad hedging concept, the four video transcripts were scanned for hedges with a cautioning function for compliance-building and safeguarding purposes. The results show that the interpreters did not follow up 
the deliberate use of hedges by the healthcare professionals. Suggestions were rendered as facts, polite and forthcoming phrasings were turned into instructions, uncertainty markers became part of embellishing statements, options were represented as decisions, balanced, emphatic or motivating expressions were over- or understated. The following describes the qualitative analysis of four doctor-patient encounters, including examples from the data. As with the phatic expressions above, it could be argued that cultural factors may have played a role, in that the interpreter may have wished to avoid a hedge for fear of sounding incompetent or of making the doctor sound hesitant, thus undermining his or her authority. However, judging from the following examples, the different placement of accent, focus and nuance by the interpreter appears to be more a lack of understanding of the significance of the hedging rather than cultural alertness on the part of the interpreter.

\subsection{Encounter One}

In Encounter One, four compliance-building and six uncertainty-marking hedges were used (in a total of $121 \mathrm{segments).} \mathrm{The} \mathrm{conversation} \mathrm{is} \mathrm{fact-oriented,}$ as it is focused on finding the source of the patient's pain and on discussing possible treatment options. Because no definite solutions are apparent in this regard, the healthcare professional uses uncertainty markers or hedges. The interpreter fails to render such forms, which signal politeness, compliance building, involvement, motivation or cautioning in the culture and medical context of the source language. Instead the interpreter presents suggestions and assumptions as facts, thus conveying certainty where there is none. Examples are as follows:

Table 2. Examples of source speech and interpretation of hedging expressions in Encounter One

\begin{tabular}{|c|c|c|c|}
\hline $\begin{array}{l}\text { Segment } \\
\text { no. }\end{array}$ & Healthcare professional & Interpreter & Hedging function \\
\hline 6 & $\begin{array}{l}\text { you would have to wait a } \\
\text { moment }\end{array}$ & $\begin{array}{l}\text { after examination you } \\
\text { wait here briefly }\end{array}$ & $\begin{array}{l}\text { politeness/ } \\
\text { compliance building }\end{array}$ \\
\hline 40 & $\begin{array}{l}\text { visiting the orthopaedic } \\
\text { specialist we looked at } \\
\text { your hips }\end{array}$ & $\begin{array}{l}\text { you went to the } \\
\text { orthopaedic specialist } \\
\text { for your hips }\end{array}$ & $\begin{array}{l}\text { involvement/ } \\
\text { compliance building }\end{array}$ \\
\hline 51 & $\begin{array}{l}\text { I admired how agile you } \\
\text { were }\end{array}$ & $\begin{array}{l}\text { I was astonished how } \\
\text { agile you were }\end{array}$ & $\begin{array}{l}\text { motivation/ } \\
\text { compliance building }\end{array}$ \\
\hline 49 & $\begin{array}{l}\text { Well, I think the pains } \\
\text { could be muscular }\end{array}$ & $\begin{array}{l}\text { highly probably the } \\
\text { pains originate from } \\
\text { the muscles }\end{array}$ & $\begin{array}{l}\text { suggestion/ } \\
\text { cautioning }\end{array}$ \\
\hline 60 & $\begin{array}{l}\text { It works like this, if you } \\
\text { file a complaint, the IV } \\
\text { [insurance] will ask for } \\
\text { our report. I would gofor } \\
\text { that option. }\end{array}$ & $\begin{array}{l}\text { if you want to file a } \\
\text { complaint, you have to } \\
\text { do that yourself at the } \\
\text { IV [insurance] }\end{array}$ & $\begin{array}{l}\text { suggestion/ } \\
\text { cautioning }\end{array}$ \\
\hline 68 & $\begin{array}{l}\text { perhaps you could even } \\
\text { write that you want a } \\
\text { medical opinion. }\end{array}$ & $\begin{array}{l}\text { you can ask for a } \\
\text { commission hearing }\end{array}$ & $\begin{array}{l}\text { suggestion/ } \\
\text { cautioning }\end{array}$ \\
\hline 87 & $\begin{array}{l}\text { I suggest that we have } \\
\text { the next ultrasound in } \\
\text { April }\end{array}$ & $\begin{array}{l}\text { then the next one } \\
\text { should be done in April }\end{array}$ & $\begin{array}{l}\text { suggestion/ } \\
\text { cautioning }\end{array}$ \\
\hline
\end{tabular}

Segment 60 involves a complete change in meaning, suggesting that the interpreter is not so much taking a target culture stance, but at times failing to render the source speech utterance adequately.

\subsection{Encounter Two}

In Encounter Two, five compliance-building and eight uncertainty-marking expressions were found (in a total of 140 segments). The conversation is for the most part about cancer treatment and the outlook/prognosis for recovery, where 
no guarantees can be given. From a medical perspective, it is important to communicate the possibility of treatment failure so that the patient can understand the situation and find a way of coping with it. It also enables the medical professional to incorporate a legal safeguard. Moreover, it is paramount to build trust by answering questions honestly, albeit cautiously. Again, assumptions are conveyed by the interpreter as facts and cautious statements about the prospects are conveyed in overly optimistic terms. The following are examples from the data:

Table 3. Examples of source speech and interpretation of hedging expressions in Encounter Two

\begin{tabular}{|l|l|l|l|}
\hline $\begin{array}{l}\text { Segment } \\
\text { no. }\end{array}$ & Healthcare professional & Interpreter & Hedging function \\
\hline 135 & then please call & do call by all means & $\begin{array}{l}\text { politeness/ } \\
\text { compliance building }\end{array}$ \\
\hline 32 & $\begin{array}{l}\text { it's supposed to last for } \\
5-6 \text { weeks, } \text { isn't it } \text { in an }\end{array}$ & $\begin{array}{l}\text { it will last for 5-6 } \\
\text { weeks }\end{array}$ & $\begin{array}{l}\text { involvement/ } \\
\text { compliance building }\end{array}$ \\
\hline 64 & $\begin{array}{l}\text { So, I think, when all } \\
\text { therapies are over, then } \\
\text { one should start this one } \\
\text { again }\end{array}$ & $\begin{array}{l}\text { When all therapies are } \\
\text { done you should } \\
\text { definitely go for this } \\
\text { other therapy again }\end{array}$ & $\begin{array}{l}\text { suggestion/ } \\
\text { cautioning }\end{array}$ \\
\hline 117 & $\begin{array}{l}\text { Ithink the fatigue comes } \\
\text { in part from the } \\
\text { consequences of the } \\
\text { chemo }\end{array}$ & $\begin{array}{l}\text { So this fatigue is a } \\
\text { consequence of the } \\
\text { chemotherapy }\end{array}$ & $\begin{array}{l}\text { assuming/ } \\
\text { cautioning }\end{array}$ \\
\hline 118 & $\begin{array}{l}\text { as far as the pains are } \\
\text { concerned, I think they } \\
\text { have to do with the } \\
\text { operation }\end{array}$ & $\begin{array}{l}\text { well he says the pains } \\
\text { stem from the } \\
\text { operation }\end{array}$ & $\begin{array}{l}\text { assuming/ } \\
\text { cautioning }\end{array}$ \\
\hline
\end{tabular}

\subsection{Encounter Three}

In Encounter Three, 30 compliance-building and two uncertainty-marking expressions were used (in a total of 465 segments). This is a reflection of the patient's desperate situation of chronic illness, which makes it necessary for the healthcare professional to show empathy, to take the patient's anxieties seriously and to motivate him or her to continue with the treatment. Moreover, there is a suggestion of the patient deliberately overdosing on medication. The doctor has to come to an assessment of the potential for suicide. To that end, $\mathrm{s} / \mathrm{he}$ has to ease the situation to allow the patient to talk about this delicate subject. This calls for emotional awareness and linguistic mindfulness on the part of the healthcare professional, which is expressed by the use of hedges. Instead of employing this cautious use of language, the interpreter tends to overinterpret, to be overly empathetic and to leave no room for the patient to develop his or her own thoughts. Examples to illustrate this are as follows:

Table 4. Examples of source speech and interpretation of hedging expressions in Encounter Three

\begin{tabular}{|c|c|c|c|}
\hline Segment no & Healthcare professional & Interpreter & Hedging function \\
\hline 247 & $\begin{array}{l}\text { Did you have the } \\
\text { impression that the } \\
\text { doctors felt you were } \\
\text { lying? }\end{array}$ & $\begin{array}{l}\text { So, the doctors felt you } \\
\text { were lying }\end{array}$ & $\begin{array}{l}\text { saving face/ } \\
\text { building compliance }\end{array}$ \\
\hline 269 & the thoughts come & $\begin{array}{l}\text { you are constantly } \\
\text { preoccupying yourself } \\
\text { with these thoughts }\end{array}$ & $\begin{array}{l}\text { saving face/ } \\
\text { building compliance }\end{array}$ \\
\hline 317 & $\begin{array}{l}\text { perhaps someone was ill } \\
\text { or something happened } \\
\text { at some point }\end{array}$ & $\begin{array}{l}\text { So, an illness, did } \\
\text { someone fall ill? }\end{array}$ & $\begin{array}{l}\text { saving face/ } \\
\text { building compliance }\end{array}$ \\
\hline
\end{tabular}




\begin{tabular}{|c|c|c|c|}
\hline 403 & $\begin{array}{l}\text { I can imagine, from what } \\
\text { you are saying, that you } \\
\text { probably feel very } \\
\text { helpless, don't you? } \\
\text { Because you do not } \\
\text { know exactly where the } \\
\text { pains come from and } \\
\text { what you can do about it } \\
\text { or what the doctors can } \\
\text { do about it }\end{array}$ & $\begin{array}{l}\text { Yes, from what I } \\
\text { understand so far, you } \\
\text { feel without help, the } \\
\text { doctors can't help, } \\
\text { nobody can help you, } \\
\text { that is why you see } \\
\text { yourself in a vacuum }\end{array}$ & $\begin{array}{l}\text { saving face/ } \\
\text { building compliance }\end{array}$ \\
\hline 452 & $\begin{array}{l}\text { Hmhm, was it also a } \\
\text { little bit a kind of a test, } \\
\text { it doesn't really matter if } \\
\text { I do not wake up again? }\end{array}$ & $\begin{array}{l}\text { Were there those } \\
\text { thoughts, well, if I } \\
\text { sleep now, nobody will } \\
\text { help, it should stay that } \\
\text { way? }\end{array}$ & $\begin{array}{l}\text { saving face/building } \\
\text { compliance }\end{array}$ \\
\hline 32 & $\begin{array}{l}\text { Can you perhaps draw } \\
\text { on here..., so that we see } \\
\text { precisely where you } \\
\text { have pain }\end{array}$ & $\begin{array}{l}\text { Can you draw on here, } \\
\text { where the pains are }\end{array}$ & $\begin{array}{l}\text { involvement/building } \\
\text { compliance }\end{array}$ \\
\hline 160 & $\begin{array}{l}\text { You are almost always } \\
\text { referred on, is that what } \\
\text { makes you angry? }\end{array}$ & $\begin{array}{l}\text { They are referring you } \\
\text { incessantly from one to } \\
\text { the other }\end{array}$ & assuming/cautioning \\
\hline
\end{tabular}

\subsection{Encounter Five}

In Encounter Five, four compliance-building and three safeguarding features can be found (in a total of 152 segments). The healthcare professional uses calming or well-considered words to explain to the patient that s/he was not able to find the cause of his or her pains. The interpreter's rendering fails to pick up on this and to convey the underlying intent. Examples are as follows:

Table 5. Examples of source speech and interpretation of hedging expressions in Encounter Five

\begin{tabular}{|l|l|l|l|}
\hline $\begin{array}{l}\text { Segment } \\
\text { no. }\end{array}$ & Healthcare professional & Interpreter & Hedging function \\
\hline 79 & $\begin{array}{l}\text { If I don't get you wrong, } \\
\text { when working, things were } \\
\text { rather better, because you } \\
\text { are a bit distracted }\end{array}$ & $\begin{array}{l}\text { He says, when you're at } \\
\text { work, you are a bit } \\
\text { distracted, you are a bit } \\
\text { better }\end{array}$ & $\begin{array}{l}\text { saving face/ } \\
\text { building compliance }\end{array}$ \\
\hline 82 & $\begin{array}{l}\text { one doesn't see anything } \\
\text { definite, that is one doesn't } \\
\text { see anything that clearly } \\
\text { explains the pains }\end{array}$ & $\begin{array}{l}\text { they could not see what } \\
\text { would explain your } \\
\text { pains }\end{array}$ & $\begin{array}{l}\text { saving face/ } \\
\text { building compliance }\end{array}$ \\
\hline 145 & $\begin{array}{l}\text { we do a check-up } \\
\text { but well it can sometimes } \\
\text { take long, these pains }\end{array}$ & $\begin{array}{l}\text { yes you will do a a long time to } \\
\text { check-up again } \\
\text { be healed }\end{array}$ & $\begin{array}{l}\text { involvement/ } \\
\text { building compliance } \\
\text { assuming/ } \\
\text { probability }\end{array}$ \\
\hline
\end{tabular}

The four analysed encounters aim to establish the patient's medical history, to provide a platform for patient and physician to get to know each other and develop a mutual trust, to record the health problems and symptoms of the patient and to outline the initial treatment plan. Language or linguistic means of expression are chosen by the healthcare professional in a deliberately cautious way with a view to not giving any false guarantees in Encounter One, to qualifying healing prospects in Encounter Two, to rebuilding compliance after the patient's negative experiences in Encounter Three and to painting a more nuanced picture of the situation in Encounter Five. In each case, the interpreter's renderings are factual and information-focused. As a result, cautious reasoning is presented as objective facts; attempts at trust and rapport building are undermined by the interpreter failing to render mitigating and empathetic nuances; suggestions are phrased as instructions; statements are misrepresented by embellishing, distorting or tampering with propositional content; and security is conveyed where there is none. 
Without going into a traditional discussion of the interpreters' role - that is, whether s/he should act as conduit, clarifier, cultural broker, and so forth and notwithstanding the underlying reasons (e.g. culture-related motives on the part of the interpreters), the examples suggest that the course of the conversation would have been better served had the interpreters more closely followed the healthcare professionals' ways of phrasing their intentions. The examples also illustrate that it takes a high degree of awareness and perhaps professionalism on the part of the interpreters for them to find adequate target language solutions for such (more or less culturally embedded) elements of healthcare communication.

\section{Discussion and conclusion}

As stated at the outset, it should be borne in mind that all three participants in the conversation contributed to the communication problems and failures found in the data of the twelve interpreted doctor-patient encounters. Overall analysis of the KTI project data suggests that all parties display a general lack of awareness of the implications and of the functional and performance specificities of interpreted communication. In fact, the healthcare professionals' ignorance of the best way to speak through interpreters - for example, their use of the third person - has been found to contribute to communication failure in other studies as well (cf. Cambridge, 1999, p. 218; Hale, 2007, p. 59). The reason why this paper focuses on the interpreters is twofold: the data reveal a pervasive tendency on their part to leave phatic expressions uninterpreted and to misrepresent nuances originally expressed by means of hedges; at the same time, the rendition of such non-content features was considered essential by the healthcare professionals involved in the project for the diagnosis and treatmentgeared purpose of the communication.

The healthcare professionals in the KTI project maintained that cultural perspectives should not be used as a major explanatory tool for these findings in the interpreter-mediated sequences; this stance is in line with Felberg and Skaaden (2012) above. Using the words of Scollon and Wong-Scollon (see above), the specialists' concern is with two individuals speaking to each other and negotiating possible cultural differences between themselves. From their perspective, it is very much part of the diagnostic and therapeutic process that both parties openly address and review such differences, something which is hindered when the interpreter steps in for clarification. They argue that it is the therapist and the patient who should come to a mutual understanding, not least with regard to their respective cultural systems or frames of reference. From their experience, interpretation, clarification, omission or re-phrasing by the interpreter are not only counter-productive with a view to the medical/therapeutic issues involved, but are also not seen as helpful by the patients - and indeed interpreters and patients, while sharing the same language, have been found to have markedly differing cultural backgrounds. Thus, Kurdish patients expressly do not wish to have their viewpoints "represented" or explained by Turkish interpreters, nor do Georgians by Russian interpreters or Ethiopians by Eritrean interpreters (nor Northern-Africans by French interpreters or Brazilians by European Portuguese interpreters, etc. - the list is endless).

When it comes to the interpreters, it should be noted that in the framework of the KTI project, it was not possible to address them in retrospective interviews to explore the reasons for non-rendition or mal-rendition of hedges and phatic expressions. It can therefore only be speculated at this point that lack of professionalism or differences in cultural background are possible causes. Further research is consequently required to shed light on the extent to which cultural traditions in patient communication influence the use of such phrases. 
Our working hypothesis would be, however, that medical interpreters often lack professional understanding of the functional significance of these expressions in therapeutic settings, similar to the way in which court interpreters have been found to disregard question-related tags and markers (see Hale, 2004, 2007). Pending further research, it might be beneficial to consider the integration of interpreting meta-discourse features into interpreter training and to emphasize the context-sensitive requirements of their use in a specific healthcare environment as a central theme in pre-encounter briefings.

Other features of doctor-patient encounters, which are more obviously culture-bound, appear to play a subordinate role in the data presented here. On one hand, they occur infrequently; on the other, they do not seem to have been of major concern for the interpreters. This may have to do with the fact that they were spoken by the patients (whereas the phatic expressions and hedges were introduced by the medical personnel). Since patients are in a more reactive rather than proactive position and find themselves in a host-culture setting, they might make less frequent use of such culture-specific expressions. Moreover, when they do, the interpreters, sharing at least some of the cultural background, may have less difficulty with these phrases. Again, while healthcare professionals would subscribe to the importance of developing an awareness of the complexities of working with culturally and linguistically diverse patient populations, they would still insist on clarifying potential differences with regard to these parts of a patient's utterance in "direct" negotiation with the patient, rather than having them explained by the interpreter.

Whether culture-bound or not, phatic and hedging expressions fulfil important cautioning, compliance-building and safeguarding functions, so that awareness of the respective functional and linguistic requirements in a particular situation may be crucial to all parties concerned. The pervasively inconsistent rendition of these expressions found in our data is summarized in the telling title of Elisabeth Glatz's (2014) BA thesis: "I would advise you..." - "The doctor says you must... [...]". To redress this imbalance between source and target language communication, preceding the encounter, a briefing of the interpreter and the healthcare professional may be the best way to address the significance of these expressions in the particular medical context; the purpose of such briefing sessions being "for the healthcare provider and the interpreter to have an opportunity to inform each other of their respective roles, expectations and requirements before the commencement of the interpreted interaction" (Hale, 2007, p. 61).

To that end, the KTI project presented here has drafted guidelines of good practice as a basis for such briefings. In fact, in conclusion, it effected two quality assurance measures aimed at improving and optimizing interpretermediated doctor-patient sessions: (1) the compilation of a terminology database (comprising 896 entries and 1524 German, 1428 Albanian, and 1485 Turkish terms) and (2) a brochure specifying guidelines of good practice in different columns for the use of both the medical personnel and the interpreter before, during, and after the session. While this brochure has met with wide appreciation and is in constant demand (the second edition of 1000 copies has been printed), it somewhat non-specifically recommends that the interpreters provide a complete rendering of parentheses and connecting phrases. As outlined above, it may be useful to address the rendering of phatic and hedging expressions more explicitly as well. Ideally, the responsible healthcare person would not only apply the listed guidelines, but would also brief the interpreter and turn briefly to the patient to inform her or him as well. In the final analysis, it is mutual understanding of the expectations, priorities and functional needs of all parties involved that ensures successful communication between all three of the agents present. It is against such a background of mutual understanding that healthcare professionals and patients should be enabled by the interpreter to engage in "direct" deliberations. 
Follow-up research should focus on the importance of rendering pragmatic features (as well as content) of interpreter-mediated communication. It should also examine the extent to which this is accomplished, the underlying reasons when it is not, and possible implications for interpreter training.

\section{References}

Angelelli, C (2004). Medical interpreting and cross-cultural communication. Cambridge: Cambridge University Press.

Cambridge, J. (1999). Information loss in bilingual medical interviews through untrained interpreters. The Translator, 5(2), 201-19.

Clemen, G. (1997). The concept of hedging: Origins, approaches and definitions. In Markkanen, R. (Ed.). Hedging and discourse. Approaches to analysis of a pragmatic phenomenon in academic texts (pp. 235-245). Berlin: de Gruyter.

Felberg, T. R., \& Skaaden, H. (2012). The (de)construction of culture in interpreter-mediated medical discourse. Linguistica Antverpiensia, New Series - Themes in Translation Studies, 11, 76-112.

Gile, D. (2009). Basic concepts and models for interpreter and translator training ( $2^{\text {nd }}$ ed.). Amsterdam and Philadelphia: John Benjamins.

Glatz, E. (2014). ,, Ich würde Ihnen raten ... “ „Der Doktor sagt, Sie müssen ... “ Eine empirische Studie über die Funktion des Hedgings im Spitaldolmetschen. (Unpublished BA dissertation, ZHAW Zurich University of Applied Sciences).

Hale, S. (2004). The discourse of court interpreting: Discourse practices of the law, the witness and the interpreter. Amsterdam and Philadelphia: John Benjamins.

Hale, S. (2007). Community interpreting. Basingstoke: Palgrave Macmillan.

Kaltenböck, G. (2010). New approaches to hedging. Bingley: Emerald.

Interpret (2015a). Retrieved 21 June 2015 from http://www.interpret.ch/ fileadmin/be_user/PDF/Interkulturelles_Dolmetschen/Liste_der_Vermittl ungsstellen.pdf

Interpret (2015b). Retrieved 21 June 2015 from http://www.inter-pret.ch/

Krystallidou, D. (2012). On mediating agents' moves and how they might affect patient centredness in mediated medical consultations. Translation Studies, 11, 75-93.

Lakoff, G. (1972). Adverbs and modal operators. Bloomington, Indiana: Indiana University.

Laver, J. (1975). Communicative functions of phatic communication. In A. Kendon, R. Harris, \& M. Key (Eds.), The organization of behaviour in face-to-face interaction (pp. 215-238). The Hague: Mouton.

Laws, M. B., Heckscher R., Mayo, S. J., Li, W., \& Wilson, I. B. (2004). A new method for evaluating the quality of medical interpretation. Medical Care, 42(1), 71-80.

Nikula, T. (1997). Interlanguage view on hedging. In R. Markkanen (Ed.), Hedging and discourse. Approaches to analysis of a pragmatic phenomenon in academic texts (pp.188-205). Berlin: de Gruyter.

Salager-Meyer, F. (1997). I think that perhaps you should. A study of hedges in written scientific discourse. In T. Miller (Ed.), Functional Approaches to Written Text (pp. 105-118). Washington, DC: United States Information Agency.

Scollon, R., \& Wong-Scollon, S.B.K. (2001). Intercultural communication: A discourse approach. Malden, MA: Blackwell.

Sleptsova, M., Hofer, G., Eggler, M., Grossman, M., Morina, N., Schick, M., Daly, M.-L., Weber, I., Kocagöncü, O. \& Langewitz, W. A. (2015). Wie 
verstehen Dolmetscher ihre Rolle in medizinischen Konsultationen und wie verhalten sie sich konkret in der Praxis? What do Interpreters Understand as their Role in a Medical Consultation and How do they Carry it out in Reality? Psychother Psych Med 2015, online publication. doi: 10.1055/s-0035-1554691.

Sleptsova, M., Hofer, G., Morina, N., \& Langewitz, W. (2014). The role of the health care interpreter in a clinical setting - a narrative review. Community Health Nursing, 31(3), 167-84. doi: 10.1080/07370016.2014.926682.

Thomas, F. N. (2013). Solution-focused supervision. A resource-oriented approach to developing clinical expertise. New York: Springer.

Wikan, U. (2002). Generous betrayal: Politics of culture in the new Europe. Chicago: University of Chicago Press. 